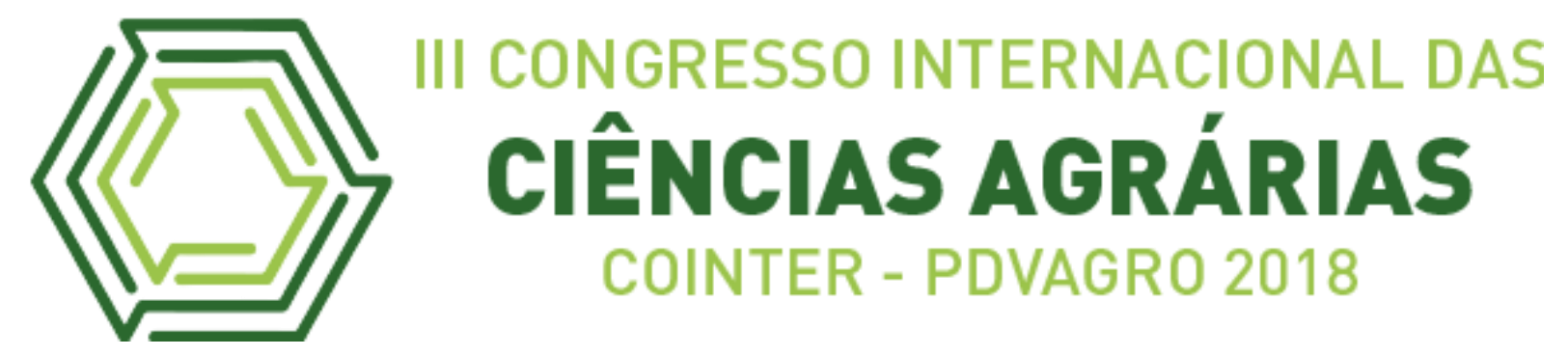

\title{
USO DE EXTRATOS VEGETAIS NO CONTROLE IN VITRO DE FUNGOS EM SEMENTES DE FEIJÃO
}

\section{USE OF VEGETABLE EXTRACTS IN VITRO CONTROL OF FUNGI IN BEAN SEEDS}

\author{
Apresentação: Pôster
}

Caroline Silva Ferreira ${ }^{1}$; Cássia Cristina Chaves Pinheiro ${ }^{2}$; Ana Karoliny Alves Santos ${ }^{3}$; Fernanda Sarmento Oliveira Louzano ${ }^{4}$; Íris Lettieri do Socorro Santos da Silva ${ }^{5}$

DOI: https://doi.org/10.31692/2526-7701.IIICOINTERPDVAGRO.2018.00687

\section{Introdução}

O feijão (Phaseolus vulgaris L.) é uma das leguminosas mais importantes para a alimentação humana em todo mundo, representando uma fonte importante de proteínas, além de conceder emprego e renda para a população (ALMEIDA, 2012). Porém, sua produção apresenta uma série de restrições, principalmente de origem sanitária, devido ao grande número de patógenos associados às sementes (SANTOS et al., 2001).

Tratamentos alternativos visando reduzir o uso de insumos químicos em sementes têm sido testados. O uso dos extratos vegetais vem crescendo gradativamente, procedente de forma natural, esses extratos são encontrados nos mais variados tipos de produtos e atraem a agricultura como alternativa sustentável (LAZAROTTO et al., 2009).

A variedade de substâncias eficazes em plantas medicinais tem atraído o crescimento de pesquisas contendo o uso de extratos vegetais com a finalidade de analisar suas propriedades. (FRANZENER et al., 2003). Os extratos são elaborados de forma concentrada, de diferentes aspectos possíveis, adquirida a partir de matéria prima vegetal seca, que passaram ou não por tratamento prévio. Diante isso, o objetivo do presente trabalho avaliar in vitro o efeito do extrato de capim santo, cravo da índia e alecrim sobre o crescimento de fungos em sementes de feijão.

\footnotetext{
${ }_{1}^{1}$ Acadêmica de Agronomia, Universidade Federal Rural da Amazônia, carolinesferreiras@gmail.com;

${ }^{2}$ Acadêmica de Agronomia, Universidade Federal Rural da Amazônia, cassiapinheiro002@gmail.com;

${ }^{3}$ Acadêmica de Agronomia, Universidade Federal Rural da Amazônia, karol.ine20@hotmail.com;

${ }^{4}$ Acadêmica de Agronomia, Universidade Federal Rural da Amazônia, feehsarmento@gmail.com;

${ }^{5}$ Dra em Fitopatologia, Professora na Área de Fitopatologia da Universidade Federal Rural da Amazônia, irislettieri@ufra.edu.br.
} 


\section{Fundamentação Teórica}

De acordo com o Ministério da Agricultura, Pecuária e Abastecimento-MAPA (2009), determinar o estado sanitário das sementes permite a obtenção de lotes de sementes de boa qualidade. Dentre os tratamentos utilizados em sementes, o químico ainda é o mais empregado por ter boa viabilidade econômica e facilidade na aplicação. É tido como um dos mais eficientes, pois além de eliminar ou reduzir o inóculo na semente (PARISI; MEDINA, 2012). Contudo a crescente preocupação quanto à agressividade de tais substâncias ao homem e ao meio ambiente por serem persistentes, podendo causar a poluição da água e do solo (CAMARGO, 2007).

O controle alternativo através do tratamento das sementes com compostos secundários obtidos de espécies vegetais no controle de fitopatógenos tem apresentado resultados satisfatórios, pois uma alta capacidade potencial das mesmas no domínio do controle de fitopatógenos (CUNICO et al., 2003), por via do seu alto grau de ação fungitóxica direta, dificultado o crescimento micelial e a germinação. A criação de uma consciência comum a respeito da indispensável necessidade de se preservar o meio ambiente vem originando uma elevada atenção a essa necessidade de não se dispensar os testes com produtos naturais tendo em vista o controle de forma alternativa de fitopatógenos (CELOTO et al., 2008).

Acredita-se até o momento, que a variedade dessas essências poderá proporcionar a aplicação direta pelo agricultor, por intermédio do cultivo da planta dentora dos compostos secundários, na organização, preparo e utilização direta do extrato nas práticas comerciais. (CELOTO et al., 2008).

\section{Metodologia}

O experimento foi realizado no Laboratório Fitopatologia da Universidade Federal Rural da Amazônia-UFRA, campi de Belém, Pará ( $1^{\circ} 27^{\prime} 31^{\prime}$ ' S e 48 26’04.5” O), durante o período de agosto de 2018.

Para preparação dos extratos, foi utilizado a metodologia adaptada de Rodrigues et al. (2006), onde foram utilizados $100 \mathrm{~g}$ de cravo-da-índia, folhas de canela e de capim santo. Estes forem triturados em liquidificador contendo $250 \mathrm{~mL}$ de água destilada esterilizada e 250 $\mathrm{mL}$ de álcool etanólico P.A. Em seguida, foram colocados em um ellermayer, por um período 96 horas, ao processo de extração por infusão. Após, os extratos foram filtrados através de papel de filtro esterilizado e mantidos em recipiente aberto, durante 72 horas, para favorecer a 
evaporação do álcool. Após esse período o material foi submetido à radiação ultravioleta por 30 minutos (UV).

As sementes de feijão, oriundas de um plantio experimental na UFRA, foram colocadas de placas de Petri contendo o meio de cultura BDA (Batata-Dextrose-Ágar), e o extrato vegetal na concentração de $15 \%$. Os tratamentos foram compostos de extrato de cravo-da-índia (T1), alecrim (T2) capim santo (T3) e o controle- com ausência de extrato vegetal- (T4) cada um contendo cinco repetições. As placas foram incubadas em BOD (Demanda Biológica de Oxigênio), com fotoperíodo de $12 \mathrm{~h}$ (claro/ escuro) à temperatura de $25 \pm 2^{\circ} \mathrm{C}$.

A avaliação foi realizada a partir de 24 horas da instalação do experimento. A da incidência de fungos nas sementes foi feita a partir da visualização dos fungos sobre as mesmas. O exame morfológico dos fungos foi feito ao microscópio (Marca Olympus, modelo CX21FS1) para a observação de detalhes morfológicos, comparando-as com a literatura pertinente de Barnett e Hunter, (1986). E para a análise, os resultados obtidos foram expressos em porcentagem de incidência de fungos descrita por Henning, (1994) e Goulart (1997). Os resultados obtidos foram submetidos à Análise de Variância e as médias foram comparadas pelo teste de Scott- Knott (p-valor $\leq 0.05$ ), utilizando-se o programa SISVAR, versão 5.6 (FERREIRA, 2011).

\section{Resultados e Discussões}

Constatou-se que os extratos vegetais testados demonstraram efeito inibitório significativo estaticamente de fitopatógenos, quando comparado com o tratamento controle (T4) como visto na figura 1.

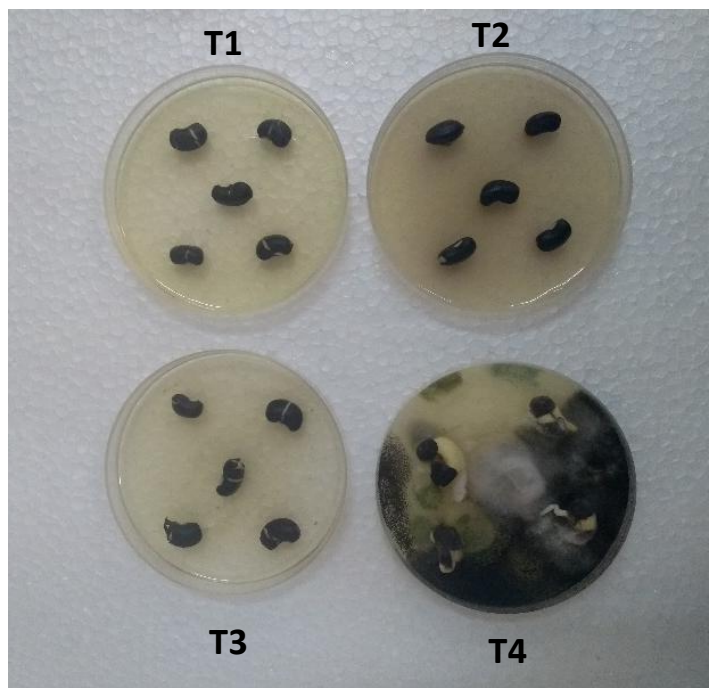


Figura 2- Sementes de feijão na presença dos extratos vegetais e o tratamento controle. Fonte: própria.

A percentagem de incidência foi de $15 \%, 20 \%$ e $17 \%$ na presença dos T1. T2 e T3 respectivamente, enquanto que no tratamento T4, a percentagem de incidência foi de $81 \%$, sendo superior, portanto, àquele na presença dos extratos, indicando a inibição do crescimento micelial na presença dos mesmos, havendo diferença estatística nos tratamentos testados (Figura 2).

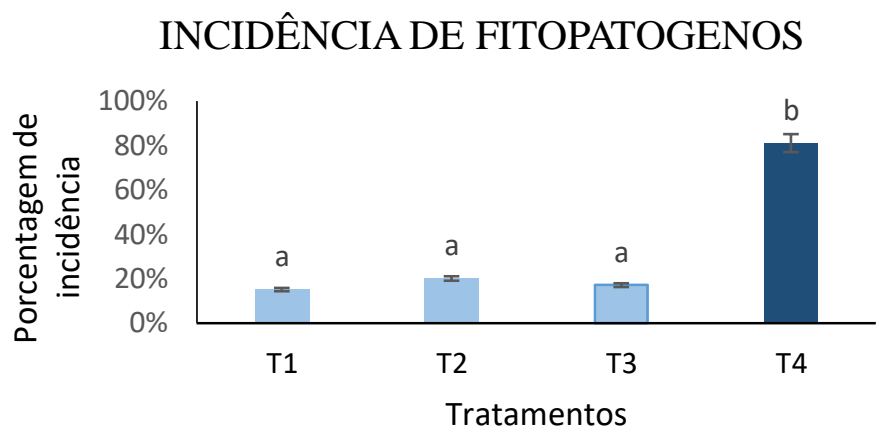

Figura 2- Percentagem de inibição de fungos na presença de extratos vegetais. Médias com letras iguais não diferem estatisticamente pelo teste de $\operatorname{Scott}-\operatorname{Knott}(\mathrm{p} \leq 0,05)$. Fonte: própria.

Em experimento realizado por Rozwalka et al. (2008), utilizando o extrato de cravoda-índia a $10 \%$ os autores não observaram crescimento de Colletrotricum gloeosporioides isolado de frutos de goiaba. E ainda, Leme et al. (2007) verificaram que a forma de esterilização e o tempo de armazenamento do extrato de capim santo interferiram na atividade do mesmo em relação ao desenvolvimento micelial de Colletotrichum acutatum.

\section{Conclusões}

Nas condições estudadas, os extratos das plantas medicinais cravo-da-índia, alecrim e capim santo apresentaram efeitos antifúngicos sobre fitopatogénos em sementes de feijão.

\section{Referências}

ALMEIDA, P. R. V. Analise de competividade potencial da cadeia exportadora de feijões brasileira. Dissertação de Mestrado em Agronegócio. Escola de Agronomia de Alimentos Universidade Federal de Goiás. CNPAF. 2012.

BARNETT, H. L.; HUNTER, B. B. Illustrated genera of imperfect fungi. 3. ed. Minneapolis, Minnesota: Burgess Publishing, 1972. 
CAMARGO, R. F. Tratamentos alternativos na qualidade sanitária e fisiológica de sementes de espécies florestais. 75 f. Dissertação de Mestrado em Engenharia Florestal - Universidade Federal de Santa Maria, 2007.

CELOTO, M. I. B.; PAPA, M. F. S.; SACRAMENTO, L. V. S.; CELOTO, F. J. Atividade antifúngica de extratos de plantas a Colletotrichum gloeosporioides. Acta Scientiarum Agronomy, Maringá, v. 30, n. 1, p. 1- 5, 2008.

CUNICO, M. M.; MIGUEL, O. G.; MIGUEL, M. D.; CARVALHO, J. L. S.; Peitz C.; AUER, C. G.; GRICOLETTI JUNIOR, A. Estudo da atividade antifúngica de Ottonia martiana Miq., Piperaceae: um teste in vivo. Visão Acadêmica, Curitiba, v.4, n.2, p.77-82, 2003.

FERREIRA, D. F. Sisvar: a computer statistical analysis system. Ciência e Agrotecnologia, Lavras, v. 35, n. 6, p. 1039-1042, 2011.

FRANZENER, G.; STANGARLIN, J. R.; SCHWAN-ESTRADA, K. R. F.; CRUZ, M. E. S. Atividade antifúngica e indução de resistência em trigo a Bipolaris sorokiniana por Artemisia camphorata. Acta Scientiarum, Maringá, v.25, n.2, p.503-507, 2003.

LAZAROTTO M, GIRARDI LB, MEZZOMO R, PIVETA G, MUNIZ MFB, BLUME E. Tratamentos Alternativos para o Controle de Patógenos em Sementes de Cedro (Cedrela fissilis). Revista Brasileira de Agroecologia; 4(2): 75- 78. 2009.

LEME, M. I. S.; CAMARGO, M.; FURLANI, A. C. F. A.; PANIZZI, R. C.; LEITE, R. F.; ROSA, J. Efeito in vitro de capim-limão no desenvolvimento micelial de Colletotrichum acutatum. Summa Phytopathologica. Botucatu, v. 33, p. 92, 2007.

MINISTÉRIO DA AGRICULTURA, PECUÁRIA E ABASTECIMENTO. Regras para análise de sementes. Brasília: MAPA/ACS, 399 p. 2009.

PARISI, J. J. D.; MEDINA, P. F. Tratamento de sementes. Instituto Agronômico de Campinas, 2013.

ROZWALKA, L.C.; LIMA, M.L.R.Z.C.; MIO, L.L.M.; NAKASHIMA, T. Extratos, decoctos e óleos essenciais de plantas medicinais e aromáticas na inibição de Glomerella cingulata e Colletotrichum gloeosporioides de frutos de goiaba. Ciência Rural, Santa Maria, v.38, n.2, p.301-307, 2008.

VIEGAS, E. C.; NASCIMENTO, F. G.; MEYRELlES, B. G.; ROSSETTO, C. A. V. Qualidade fisiológica de sementes armazenadas de amendoim influenciada pelos produtos sintéticos e de origem vegetal. Revista Brasileira de Plantas Medicinais, Botucatu, v.7, n.3, 2005. 